\title{
Testing a Rapid Climate Change Adaptation Assessment for Water and Sanitation providers in informal settlements in 3 cities in sub- Saharan Africa
}

\author{
Tom T. Heath, Alison H. Parker and E. Keith Weatherhead
}

Alison Parker is the Academic Fellow in International Water and Sanitation in the Cranfield Water Science Institute while Keith Weatherhead is the Reader in Climate Change

Adaptation in this Institute. Tom Heath was a KTP Associate with Water and Sanitation for the Urban Poor and a MSc by Research student at Cranfield University.

Address: Cranfield Water Science Institute, Cranfield University, Cranfield, Bedfordshire, MK43 0AL, UK, E-mails: theath@gmail.com ; a.parker@cranfield.ac.uk; and k.weatherhead@cranfield.ac.uk

Water and Sanitation for the Urban Poor (WSUP) and the Technology Strategy Board (grant number sKTP 1000074) are acknowledged for their funding of this project. WSUP staff in Kenya, Zambia, Madagascar and the UK are thanked for their facilitation of the field visits. Two anonymous reviewers are acknowledged for their comments which have improved and clarified the paper.

\begin{abstract}
Climate change is expected to affect the poor in low- and middle income countries most, particularly in the next few decades through increased floods and droughts. A very large number of these live in informal urban settlements where they rely on water kiosks and pit latrines and usually with inadequate provision for drainage. Despite an abundance of climate change publications, there is little advice specific to those providing water and sanitation services to the urban poor in these countries. This paper presents a Rapid Climate Adaptation Assessment (RCAA) for water and sanitation providers that leads to recommendations climate proofing local service providers, utilities and local governments. Overall, the RCAA converts regional climate predictions into recommendations for local adaptations. The methodology was developed through field work with communities in Lusaka (Zambia), Naivasha (Kenya) and Antananarivo (Madagascar). This paper describes the methodology, summarises the results of its application (and the implications for adaptation) and discusses its wider application and limitations. In most cases, the proposed adaptations are not new actions, and could be described as 'good water management'.
\end{abstract}

Key Words: Climate change impacts and adaptation, informal settlements, water, sanitation 


\section{Introduction}

There are a wide range of uncertainties associated with predictions of anthropogenic climate change ${ }^{1}$; however, the scientific community now widely accept that it is a reality ${ }^{2}$. Water is one of the primary media through which climate change will influence the Earth's ecosystems ${ }^{3}$ and people's livelihoods ${ }^{4}$. Changes in rainfall patterns, amounts and intensities will increase the risk of floods and droughts ${ }^{5}$ and exacerbate current stresses on water resources. Africa is the continent most vulnerable to climate change ${ }^{6}$ and the poor are more vulnerable to climate change than the population as a whole ${ }^{7}$ majority of these poor live in ecologically fragile zones and are heavily dependent on natural resources and sectors which are vulnerable to climate variability - for example a third of the African population live in drought prone areas ${ }^{8}$. The Stern Report ${ }^{9}$ predicted that by 2100 between 145 and 220 million additional people in South Asia and sub-Saharan Africa could fall below the \$2-a-day poverty line, and every year an additional 165,000 to 250,000 children could die compared to a world without climate change.

\footnotetext{
${ }^{1}$ UNWATER (2009), The United Nations World Water Development Report 3. Chapter 5 Climate Change and Possible Futures. WWDR 021609.indd 68 UNESCO World Water Assessment Programme UNWATER. Available at: www.unwater.org/downloads/15_WWDR3_ch_5.pdf (Accessed: June 2010).

${ }^{2}$ Royal Society (2010), Climate change: a summary of the science. Available at: royalsociety.org/climatechange-summary-of-science/ (Accessed: October 2010).

${ }^{3}$ UNESCO-WWAP (2009), Climate change and water: an overview from the World water development report 3: water in a changing world. A WORLD WATER ASSESSMENT PROGRAMME SPECIAL REPORT. SC2010/WS/5. unesdoc.unesco.org/images/0018/001863/186318e.pdf (Accessed: October 2010).

${ }^{4}$ UNWATER (2010), Climate Change Adaptation: The Pivotal Role of Water. Policy Brief. Available at: www.unwater.org/downloads/unw_ccpol_web.pdf (Accessed: October 2010).

${ }^{5}$ Hadley Centre, 2005. Stabilizing Climate to Avoid Dangerous Climate Change - a Summary of Relevant Research at the Hadley Centre. Available at: www.metoffice.gov.uk/research/hadleycentre/pubs/brochures/2005/CLIMATE_CHANGE_JOURNAL_150.Pdf (Accessed: October 2010); Laukkonen, J., Blanco, P., K., Lenhart, J., Keiner, M., Cavric, B., \& KinuthiaNjenga, C. (2009), Combining climate change adaptation and mitigation measures at the local level, Habitat International. 33 (3) pp. 287-292; and Parry, M., Osvaldo C., Palutikof, J.,van der Linden, P. \&Hanson, C. (2007), Climate Change 2007: Impacts, Adaptation and Vulnerability,, Contribution of Working Group II to the Fourth Assessment Report of the Intergovernmental Panel on Climate Change, Cambridge University Press, Cambridge and New York

${ }^{6}$ See reference 5 , Parry et al (2007)

${ }^{7}$ Africa Partnership Forum (2008), Climate challenges to Africa: a call for action; [cited 2009 March 15]. Available at: www.africapartnershipforum.org (Accessed: October 2010); World Bank (2009), World development report 2010: development in changing climate: concept note; [cited 2009 April 16]. Available at: www.worldbank.org (Accessed: October 2010); Nyong, A. (2009), Climate change impacts in the developing world: implications for sustainable development. In: Brainard L, Jones A, Purvis N, editors. Climate change and global poverty: a billion lives in the balance? Washington (DC): Brookings Institution Press. pp. 43-64; and Parry et al 2007, see reference 5 .

${ }^{8}$ Hope Sr., K., R., (2009), Climate change and poverty in Africa, International Journal of Sustainable Development and World Ecology. 16 (6) pp. 451-461.

${ }^{9}$ Stern, N. (2006), Stern review: The economics of climate change. Cambridge: Cambridge University Press.
} 
In Africa, climate change impacts will be compounded by population growth ${ }^{10}$, and the damage to livelihoods and resources is widely expected to increase migration into the cities ${ }^{11}$ (although this is disputed by Potts (2009) ${ }^{12}$.

Since 1990 the urban population of Sub-Saharan Africa has more than doubled, yet the proportion of people without access to improved drinking water sources (17\%) and sanitation facilities $(57 \%)$ has remained constant ${ }^{13}$. The poor who lack access often live on marginal land in flood-prone areas ${ }^{14}$. Where safe and legal water supplies do exist, these are often provided through water kiosks which are in turn supplied by the main water utility or a local source. The kiosks can be operated by a local service provider and have independent management, but are supported and regulated through the city's main utility. Water kiosks are still a compromise compared to household connections as water still needs to be carried to and stored in the home, which has its own time penalties and water safety risks for the families involved. However, household connections require more complicated legal and financial arrangements ${ }^{15}$, which are undesirable to water utilities. The "local service providers" who operate the kiosks are better able to cope with the informal nature of periurban and informal areas although they are limited by lack of finance and technical capacity. Similarly, the urban poor are rarely connected to the sewage network and so are forced to use on-site sanitation like pit latrines. Depending on national and local regulations, this may fall under the responsibility of the utility or the municipality, or it may fall between them and rely on the informal sector. Again, there is limited finance and technical capacity.

Climate change will severely impact these service providers. Current water management and sanitation practices may not be robust enough to cope with the impacts ${ }^{16}$. Sub-Saharan African utilities' adaptations have mostly been 'adhoc', only addressing short term concerns, and have yet to address climate vulnerability more systematically ${ }^{17}$. Many practitioners argue that it is not yet possible for water managers in low- and middle-income countries to take

${ }^{10}$ Carter, R.C. and Parker, A.H. (2009), Climate change, population trends and groundwater in Africa. Hydrological Sciences-Journal-des Sciences Hydrologiques. 54(4) Special issue: Groundwater and Climate in Africa, 676-689, 2009

${ }^{11}$ Barrios, S., Bertinelli, L., \& Strobl, E., (2006), Climatic change and rural-urban migration: The case of subSaharan Africa, Journal of Urban Economics. 60 (3) pp. 357-371.

${ }^{12}$ Potts, D. (2009), "The slowing of sub-Saharan Africa's urbanization: evidence and implications for urban livelihoods", Environment and Urbanization, 21,(1), pp 253-259.

13 WHO and UNICEF, Joint Monitoring Programme for Water Supply and Sanitation, Data and estimates.

Available at: http://www.wssinfo.org/data-estimates/graphs/ (Accessed January 2012)

${ }^{14}$ See reference 1 , UNWATER (2009)

${ }^{15}$ WSUP (2011) Helping people connect to water networks: good for business, good for the poor? Practice Note 7, Available at: http://www.wsup.com/sharing/documents/PN007HelpingConnectToWaterNetworks.pdf (Accessed: January 2012)

${ }^{16}$ Bates, B.,C., Kundzewicz, Z.,W., W.,S., Palutikof, J.,P., editors. (2008), Climate change and water: IPCC technical paper VI. Geneva: IPCC Secretariat. Available at:

www.ipcc.ch/publications_and_data/publications_and_data_technical_papers.shtml (Accessed: October 2010).

${ }^{17}$ Danilenko, A., Dickson, E., \& Jacobsen, M. (2010), Climate change and urban water utilities: challenges \& opportunities. (Water working notes ; no. 24). Washington, DC, USA. Water Sector Board, Sustainable Development Network, World Bank. Available at :

www.wsp.org/wsp/sites/wsp.org/files/publications/climate_change_urban_water_challenges.pdf (Accessed: October 2010). 
climate change into account ${ }^{18}$ because they are struggling to cope with day-to-day management. However, adapting to present climate variability (increasing resilience, reducing vulnerability) is already an integral part of water management - the efficiency and success depends upon the utilities' governance ${ }^{19}$ - and longer-term adaptation can build on this.

There are efforts underway at many levels of government, and within international institutions, to prepare adaptation to climate change ${ }^{20}$ - especially in the water resources sector $^{21}$. However, a thorough vulnerability analysis and impact assessment for enabling appropriate design and implementation of adaptation measures is lacking in almost all lowand middle-income countries ${ }^{22}$. There needs to be a shift from generic global impact assessments to more locally focused adaptation and response mechanisms ${ }^{23}$, and adaptations need to focus on increasing the resilience of water providers to climate variability ${ }^{24}$. Adaptation policies work best when climate change initiatives link adaptation and development, addressing the structural conditions causing vulnerability ${ }^{25}$ it also needs to be recognised that future long term changes can introduce new unexpected risks to projects ${ }^{26}$.

So far there has been little focus on water supply and sanitation for the urban poor. The most relevant studies are the DFiD WHO Vision $2030^{27}$ review, the CRiSTAL ${ }^{28}$ methodology and USAID Methodologies $^{29}$. Vision 2030 comprehensively overviews the resilience of water and sanitation technologies, but lacks information on replication or assessing vulnerability.

\footnotetext{
${ }^{18}$ See reference 5, Lauukkonen et al (2009).

${ }^{19}$ Batcherlor, C., Schouten, T., Smit., S., Moriarty, P., \& Butterworth, J. (2009), Climate Change and WASH Services Delivery - Is Improved WASH Governance the Key to Effective Mitigation and Adaptation? Perspectives on Water and Climate Change Adaptation. IRC International Water and Sanitation Centre. World Water Council. Available at :www.wsscc.org/resources/resource-publications/climate-change-and-washservices-delivery-\%E2\%80\%93-improved-wash-governance?rck=94d467d83a49eab7df3e7ba6e6cec619 (Accessed: October 2010).

${ }^{20}$ The Heinz Center (2006), A Survey of Climate Change Adaptation Planning. The H. John Heinz center for Science, Economics and the Environment. Washington, DC. Available at: www.heinzctr.org/publications/PDF/Adaptation_Report_October_10_2007.pdf (Accessed: October 2010). ${ }^{21}$ See reference 19, Batcherlor et al (2009).

${ }^{22}$ Nath, P. K. \& Behera, B. (2010), A critical review of impact of and adaptation to climate change in developed and developing economies, Environment, Development and Sustainability. 13 (1) pp. 141-162.

${ }^{23}$ See reference 19, Batcherlor et al (2009).

${ }^{24}$ Muller, M. (2007), Adapting to climate change: Water management for urban resilience, Environment and Urbanization. 19 (1) pp. 99-113.

${ }^{25}$ Sanchez-Rodriguez, R. (2009), Learning to adapt to climate change in urban areas. A review. Current Opinion in Environmental Sustainability 1 pp. 201-206; Simon, D., (2010), WP/51 The Challenges of Global Environmental Change for Urban Africa. UNU-Wider 2010/51. Available at :

www.wider.unu.edu/publications/working-papers/2010/en_GB/wp2010-51/ (Accessed: August 2010).

${ }^{26}$ USAID (2007), Adapting to climate variability and change a guidance manual for development planning Available e at: www.usaid.gov/our_work/environment/climate/docs/reports/cc_vamanual.pdf (Accessed: October 2010).

${ }^{27}$ Howard, G., Charles, K., Pond, K., Brookshaw., Hossain, R., \& Bartram, J. (2010), Securing 2020 vision for 2030: climate change and ensuring resilience in water and sanitation services. Journal of Water and Climate Change 1 pp. 1 2-16.

${ }^{28}$ IISD (2009), CRiSTAL: Community-based Risk Screening Tool - Adaptation and Livelihoods. International institute for Sustainable Development. Stockholm Environment Institute. Intercooperation - Swiss Foundation for Development and International Cooperation. International Union for Conservation of Nature. Available at: www.cristaltool.org/ (Accessed: June 2010).

${ }^{29}$ See reference 26, USAID (2007).
} 
The other methodologies overview community vulnerability and adaptation but lack a water or sanitation focus. To fill this gap, this paper presents a Rapid Climate Adaptation Assessment (RCAA) developed specifically for water and sanitation supply for the urban poor. The RCAA assesses how changes to climate interact with existing vulnerabilities in peri-urban and informal areas, and then recommends adaptations to the existing plans of water providers to increase their climate resilience.

\section{Method}

The RCAA was developed in Lusaka, Zambia, then trialled in two other case study cities: Naivasha, Kenya and Antananarivo, Madagascar. These cities were selected as they are part of the international programme of Water and Sanitation for the Urban Poor (WSUP), a trisector partnership between the private sector, civil society and academia focused on addressing the increasing global problem of inadequate access to water and sanitation for the urban poor.

The RCAA consists of 5 stages: [1] a literature review, to identify the impacts of climate change; [2] field work, to assess the existing vulnerabilities of communities and water providers; [3] preparation of hydrological scenarios; [4] assessment of the impact of the scenarios on the community; and [5] identification, selection and recommendation of adaptations to climate proof the water and sanitation services. The research also allowed an opportunity to assess the overall awareness of climate change among the different stakeholders, as well as their current plans for adaptation.

Each stage is discussed in turn:

\subsection{Literature Review}

A literature review was first undertaken for each city using key climate change resources. Sources such as those outlined in Table 1 are likely to be available for most localities; country-specific resources were used where they were available. The purpose was to identify the likely changes to climate and the resulting impacts upon water resources, health, livelihoods and biodiversity, as these will all impact the population's access to water and sanitation services.

Table 1 Key resources for literature review available of any low income country

\begin{tabular}{|l|l|l|}
\hline Documents & Description & Key sections \\
\hline $\begin{array}{l}\text { National Adaption } \\
\begin{array}{l}\text { Programme for } \\
\text { Action (NAPA) }\end{array}\end{array}$ & $\begin{array}{l}\text { Details the urgent and immediate needs } \\
\text { and concerns of low and middle income } \\
\text { countries relating to adaptation to the } \\
\text { adverse effects of climate change }\end{array}$ & $\begin{array}{l}\text { Section 2: Framework for the } \\
\text { Adaptation Programme; Appendix: } \\
\text { Proposed Adaptations }\end{array}$ \\
\hline National & Details the results of national assessments & Chapter 1: National Circumstances and \\
\hline
\end{tabular}

${ }^{30}$ UNFCCC submitted NAPA. Available at:

unfccc.int/cooperation_support/least_developed_countries_portal/submitted_napas/items/4585.php(Accessed: October 2010). 


\begin{tabular}{|l|l|l|}
\hline $\begin{array}{l}\text { Communications to } \\
\begin{array}{l}\text { United Nations } \\
\text { Convention on } \\
\text { Climate Change }\end{array}\end{array}$ & $\begin{array}{l}\text { of greenhouse gas emissions, as well as } \\
\text { information on vulnerability, impacts, and } \\
\text { adaptation. Observed and anticipated } \\
\text { trends and impacts of climate change for } \\
\text { each country can be drawn from these } \\
\text { documents }\end{array}$ & $\begin{array}{l}\text { Chapter 4: Vulnerability and Adaption } \\
\text { Assessment }\end{array}$ \\
\hline $\begin{array}{l}\text { UNDP Climate } \\
\text { Change Country } \\
\text { Profiles }\end{array}$ & $\begin{array}{l}\text { Country-level studies of climate } \\
\text { observations and multi-model projections } \\
\text { for 52 countries }\end{array}$ & $\begin{array}{l}\text { Trends GCM; Projections of Future } \\
\text { Climate; Other Regional Climate } \\
\text { Change Information; Data Summary }\end{array}$ \\
\hline
\end{tabular}

\subsection{Fieldwork - Vulnerability Assessment}

Semi-structured interviews, community focus groups and direct observation were undertaken during two weeks fieldwork in each of the cities. The initial interviews were arranged with representatives of the local water and sanitation service providers, water utility, meteorological organisation, municipality and with researchers identified in the literature review. During these interviews, stakeholders were asked to name other stakeholders who might provide useful insights; these included representatives from regional government, the scientific community and NGOs. The total numbers interviewed are detailed in Table 2.

Table 2 Number of interviews with each stakeholder for the 3 case studies

\begin{tabular}{|l|l|l|c|}
\hline Stakeholder & Lusaka & Naivasha & Antananarivo \\
\hline Community individuals & 10 & 10 & 2 \\
\hline Community focus groups & 1 & 2 & 8 \\
\hline Local service providers & 12 & 2 & 2 \\
\hline Utility & 2 & 2 & 1 \\
\hline Municipality & 3 & 2 & 2 \\
\hline Government & 8 & 7 & 4 \\
\hline Researchers & 2 & 1 & - \\
\hline NGOs & 3 & 3 & 7 \\
\hline Consultants & - & - & 2 \\
\hline Local business & - & 2 & 2 \\
\hline
\end{tabular}

The questions varied in the level of technical detail and the topics covered depending on the stakeholders' roles. A priority was clarifying the local causes and impacts of floods and droughts, the adaptations required and any existing development plans. The topics discussed included:

- The interviewees' understanding of climate change, its impacts and adaptation;

- The interviewees' understanding of the predicted changes for their locality;

- The impacts of changes in temperatures, mean hydrological parameters (e.g. in rainfall amount or intensity) and extreme hydrological events (e.g. floods, droughts) on the water and sanitation technologies and services for these communities;

- The impacts of climate change not directly related to water and sanitation;

\footnotetext{
31 UNFCCC submitted non-annex Nation Communications. Available at: unfccc.int/national_reports/nonannex_i_natcom/submitted_natcom/items/653.php(Accessed: October 2010).

32 UNDP Climate Change Country Profiles. Available at: country-profiles.geog.ox.ac.uk/ (Accessed: October 2010).
} 
- Current water resources, including abstractions, discharges and management, and whether the current level of abstraction is sustainable;

- The current procedures and future plans of the water providers;

- How the community and local service providers adapt during current extreme events.

Community focus groups were organised with 8-16 people (the aim was for 8-10, but more attended), using a translator. The groups were asked to discuss floods (where they occurred) followed by droughts (where they occurred). Then the events prior to and during past floods (or droughts) were discussed. This included questions on when the last event was, how often they occur, how much warning there is, their duration and whether there have been any noticeable changes in their frequency or nature. The impact on the community was then discussed including livelihoods, education, water supply, sanitation, health, buildings, women, food prices, fuel prices and the community as a whole. The focus group were then asked to identify the largest problem. Following this, adaptation was discussed, debating the best ways to adapt, reviewing who is responsible and the perceived role of local government, CBOs and NGOs.

Direct observation was used to verify the responses in interviews and focus groups. This included general surveillance of hygiene practices, drainage and buildings, for example checking the quality of drainage channels, construction of latrines, hygiene standards and looking for water marks and other indicators of flooding.

\subsection{Hydrological Scenario Development}

There are rarely hydrological models which can easily show how predicted climate changes would impact the local hydrology of the areas under consideration, and developing them in a rapid assessment would be impractical due to the cost, lack of data and the time required. Simple conceptual hydrological models for each city were therefore developed, based on the field data. A small number of key scenarios were then tested based on the climate change predictions for the region. These scenarios show qualitatively the potential effects on any rivers, lakes, ground water and runoff levels. For example, in Antananarivo runoff is already high, which indicates the infiltration capacity is frequently exceeded, therefore future increases in rainfall intensity are likely to further increase runoff.

This analysis was used to assess if there was a local risk from any of the following:

- Increased flooding

- Increased groundwater recharge and a rise in groundwater level

- Increased runoff with more erosion

- Decreased surface water availability

- Decreased groundwater levels 


\subsection{Impact Assessment}

The effects of these hydrological scenarios on existing vulnerabilities in water and sanitation were first qualitatively reviewed using Vision 2030 reports. For example, Vision 2030 identifies that a borehole may be vulnerable to increased contamination of groundwater from lateral flow in soil or inundation of the well from an increased risk of flooding, and then lists the possible adaptations. Then the impacts not directly related to water and sanitation, such as changes in food prices, electricity prices or employment, were assessed. Finally, the existing plans were analysed to identify new risks, areas lacking resilience and aspects of the plans which could be vulnerable.

\subsection{Climate Proofing}

Finally, a set of recommended adaptations were developed for service providers. Suggested adaptations from the focus groups and interviews were reviewed together with the adaptations recommended for the specific technologies from Vision 2030. Adaptations were sought that improved the systems' current resilience to climate variability, were appropriate to the service providers and addressed actual risks. Adaptations were made specific to the local service provider, water utility or municipality and were subdivided according to timescale $^{33}$ and between the following categories ${ }^{34}$ :

- Capital expenditure

- Operational expenditure

- Monitoring

- Social economic

\section{Results from the case studies}

This section summarises the findings and recommendations resulting from the three case studies, in Antananarivo, Naivasha and Lusaka. For more detail, the comprehensive country reports can be downloaded ${ }^{35}$

\subsection{Lusaka - Zambia}

\footnotetext{
${ }^{33}$ Venton, P., Cacouris, J., \& Cabot, C. (2010), How to integrate climate change adaptation into national-level policy and planning in the water sector: a practical guide for developing country governments. TEARFUND. Available at: tilz.tearfund.org/webdocs/Tilz/Topics/watsan/Water\%20Adaptation\%20Guide_Web.pdf (Accessed: October 2010).

${ }^{34}$ Charles, K., Pond, K., \& Pedley, S. (2010), Vision 2030: The resilience of water supply and sanitation in the face of climate change. Technology fact sheets. University of Surrey. Available at :

www.who.int/water_sanitation_health/publications/vision_2030_technology_fact_sheets.pdf (Accessed: October 2010).

${ }^{35}$ The three city reports by Heath, T., Parker, A., \& Weatherhead, E., K. (2010) are available: How to climate proof water and sanitation services in the peri-urban areas in Lusaka; How to climate proof water and sanitation services in the peri-urban areas in Naivasha; and How to climate proof water and sanitation services in the informal areas and peri-urban areas in Antananarivo. Reports prepared by Cranfield University. WSUP, London. Available at: www.wsup.com/sharing/Resources.htm (Accessed: October 2010).
} 


\subsubsection{Background}

Despite having $40 \%$ of Southern Africa's water resources ${ }^{36}$, Zambia experiences water scarcity. This is due to a combination of seasonal and temporal rainfall patterns and limited investment in infrastructure. The field work focused upon two peri-urban areas in Lusaka Chazanga and Kanyama ${ }^{37}$. Chazanga is north of the city centre, is hilly and has a population of 35,000 (2007). Kanyama is south east of the city and has a population of 198,000 (2007). Kanyama is very flat, rocky and is the natural drainage plain for the city; as a result it experiences severe flooding. Water is supplied to both areas by community cooperatives (Water Trusts), using boreholes and kiosks, which are licensed by the city's main water utility via a Memorandum of Understanding. The community also uses shallow wells for water. This should be for non-consumptive use but some families do use it for drinking water if they cannot afford or do not want to use kiosk water. Sanitation facilities are pit latrines although there are some ecosan programmes, and some efforts to elevate latrines.

\subsubsection{Climate Change}

The main risks from climate change facing Zambia are an expected increase in floods and droughts combined with a reduction in Miombo woodland and maize yields. ${ }^{38}$ The mean temperature is predicted to increase with a greater frequency of 'hot' days and nights and very few 'cold' days or nights. Total rainfall and rainfall intensity are expected to increase in summer and the frequency and intensity of extreme events, principally droughts and floods, is expected to increase.

\subsubsection{Hydrological Scenarios}

Two scenarios were developed for Lusaka, based around precipitation changes. Increasing precipitation would be likely to increase the level of the main river (Kafue) and groundwater and increase the intensity of localised flooding. Decreasing precipitation would be likely to lower the groundwater level - the majority of interviewees believed that current groundwater abstractions were greater than recharge and hence were already unsustainable.

\subsubsection{Vulnerabilities and Impacts}

Chazanga is most vulnerable to a decrease in rainfall and a lower water table, increasing the likelihood of water scarcity, damage to water kiosks and pipes and drying up of shallow wells, all of which will increase the demand for new kiosks. Decreased rainfall could also

\footnotetext{
${ }^{36}$ Zambia: National Adaption Plan for Action (2007), UN supported process to identify priority activities and immediate needs with regard to adaptation to climate change. Available at: www.preventionweb.net/files/8581_zmb01.pdf (Accessed: May 2010).

${ }^{37}$ WSUP (2008), Lusaka Peri-urban Water and Sanitation 2008. London.

${ }^{38}$ Heath, T. (2010), Zambia Climate Change Briefing. WSUP Cranfield University. Available at: www.wsup.com/sharing/Resources.htm (Accessed: October 2010); Ministry of Tourism, Environment and Natural Resources, (2007) Formulation of the national adaptation programme of action on climate change, September 2007, UNDP, Zambia. Available at: http://unfccc.int/resource/docs/napa/zmb01.pdf (Accessed March 2012)
} 
affect hydroelectric generation, causing power shortages. However, if rainfall or rainfall intensity doesincrease, flash floods are likely to damage boreholes, kiosks, septic tanks and pit latrines and the poor drainage at kiosks would be exacerbated. Lastly, there is likely to be an increase in climate-driven migrations to the area, increasing land pressure and exacerbating the problems associated with the limited latrine emptying options.

In contrast, Kanyama is most vulnerable to an increase in rainfall, resulting in an increase in flooding - the 2009-10 flood lasted for 3 months. Flooding causes kiosks and buildings to collapse, contaminates water supplies (particularly the shallow wells used in the areas unserved by the kiosks) and affects livelihoods, education and health. Flooded latrines and contaminated water increase the risk of cholera and diarrhoea. A decrease in rainfall could be beneficial for Kanyama, reducing the likelihood of flooding.

\subsubsection{Climate Proofing}

In Chazanga, water shortages due to power failure could be mitigated by acquiring a generator; in the longer term, the Chazanga Water Trust need to investigate alternative sources of water and/or deepen their boreholes. To protect infrastructure from heavy rainfall, the soil needs to be stabilised with buffer strips and erosion control measures and drainage standards for soakaways need to be improved. This will reduce surface run off and prevent it building into high energy torrents that undermine kiosks and damage pipes.

In Kanyama, reducing localised flooding should be the priority. This entails working with the council and utility to develop the drains and clear them of rock and debris. The main health risks arise from latrines being inundated by floodwater and overflowing. Possible adaptations are assistance in emptying and raising latrines, and in the longer term installing decentralised sewerage; however, all the adaptations would rely on improved drainage and the worst latrines are owned by the poor who cannot afford to upgrade. To improve drainage, the local water utility (Lusaka Water and Sewage Company) need to provide technical support and assist in mobilising finance, while the council need to establish better planning and zoning legislation. In addition, to improve the health of the community the water kiosk network needs to be expanded to ensure every household is close enough to a water kiosk so they can access safe water during floods.

\subsection{Naivasha - Kenya}

\subsubsection{Background}

Naivasha is sited approximately 50km north west of Nairobi, next to Lake Naivasha. Profitable and expanding flower and vegetable farms $\left(4000 \mathrm{ha}^{40}\right)$ surround the lake, exporting to Europe and providing the basis of the local economy. These have led to a rapid growth in

\footnotetext{
${ }^{40}$ Becht, R., Odada, E.,O., \& Higgins, S. (2005), Lake Naivasha : experience and lessons learned brief. In: Lake basin management initiative : Experience and lessons learned briefs. including the final report: Managing lakes and basins for sustainable use, a report for lake basin managers and stakeholders. Kusatsu : International Lake Environment Committe Foundation (ILEC), 2005. pp. 277-298. Available at: www.ilec.or.jp/eg/lbmi/pdf/17_Lake_Naivasha_27February2006.pdf (Accessed: August 2010).
} 
population, as confirmed by interviews and Becht et al $2005^{41}$ The farms abstract from the lake and employ cheap labour from the peri-urban areas; there is conflict over declining water levels, increasing pollution and poor working conditions. Three peri-urban communities were visited, Karagita, Kamera and Mirera (population 54,000 (1999) ${ }^{42}$ ). Groundwater is abstracted and supplied via kiosks by a small private network operator under agreement with the water utility, Naivawass. Some water is collected directly from the lake and delivered by donkey carts. The communities suffer from droughts as well as flash floods which drain into the lake. Sanitation facilities are pit latrines.

\subsubsection{Climate Change}

Kenya is classified by the UN as chronically water-scarce ${ }^{43}$. Agriculture is the basis of the economy, employing $75 \%$ of the population and providing the largest proportion by sector of the $\mathrm{GDP}^{44}$ and is very vulnerable to increasing temperatures, droughts and floods. Mean temperature is predicted to increase with a greater frequency of 'hot' days and nights and very few 'cold' days or nights. Rainfall is anticipated to decrease in volume, increase in intensity and become increasingly irregular (observable in recent years). Extreme events will increase in frequency and intensity and occur in new locations.

\subsubsection{Hydrological Scenarios}

Two scenarios were developed based around changes in the mean lake levels. Decreasing lake levels and increased drought would occur if there were significant increases in evaporation and/or decreases in rainfall. Increasing lake levels would occur if there was increased rainfall intensity in the upper catchment leading to increased runoff and river flow, offsetting potential increases in lake evaporation. Increased rainfall intensity would also increase the number and intensity of flash floods.

\subsubsection{Vulnerabilities and Impacts}

Decreasing lake levels and increased drought would result in increased domestic demand and a decrease in the availability of surface waters. In the past borehole levels have remained constant through droughts, so there is hope that this would still be the case in the future. However the shallow wells dry up, so there are longer queues at kiosks, water from vendors becomes more expensive and water takes longer to collect. The community cite the main problem during droughts as a decrease in household income, because the flower farms reduce their workforce, and market gardening becomes impossible. It means households are less

\footnotetext{
${ }^{41}$ See reference 40 , Becht et al (2005),

${ }^{42}$ WSUP (2006), Feasibility Study on Improvement of Water and Sanitation Conditions for Mirera-Karagita: Naivasha Final Report October 2006. Development Impact Consulting. London.

${ }^{43}$ World Bank (2009), Climate Variability and Water Resources Degradation in Kenya: Improving Water Resources Development and Management. Working Paper No. 69 34854. Available at: www.wds. worldbank.org/external/default/main?pagePK=64193027\&piPK=64187937\&theSitePK=523679\&me nuPK=64187510\&searchMenuPK=64187 283\&siteName=WDS\&entityID=000090341_20060110161654 (Accessed: October 2010).

44 Library of Congress - Federal Research Diviion (2007) Country Profile: Kenya. Available at: http://lcweb2.loc.gov/frd/cs/profiles/Kenya.pdf (Accessed January 2012)
} 
able to pay for water and food, compounded by the increases in food prices. As a result, water use decreases, hygiene deteriorates and the prevalence of disease increases.

As the lake is very shallow, the lake area decreases as the level drops, leading to conflict over abstractions between pastoralists and the commercial farms. Without adequate water, the commercial farms would become unprofitable and reduce their workforce, leading to unemployment. When the lake volume decreases, water quality also deteriorates.

An increase in flash floods would also create problems for the community. Flash floods wash solid waste and silt into the lake, cause latrines to collapse and overflow, expose pipes, damage houses and crops and inundate roads which disrupt local businesses and schools. The community emphasised that flash floods are only an inconvenience, but a health professional reported an increase in diarrhoea, typhoid and dysentery during floods.

\subsubsection{Climate Proofing}

The private network operator needs to ensure affordable and accessible water by maintaining low prices at the kiosks. They should support catchment management processes, ensure well heads are properly sealed and provide education about flood proof latrines. These would be pits that are sealed so they cannot become flooded with groundwater, and raised above ground level so that they cannot be inundated by surface water. The water utility (Naivawass) need to adapt their system to better cope with flash floods, especially their sewage treatment plant which becomes overloaded with stormwater during rain events (although this plant only serves a small proportion of the population). The council need to maintain and develop drains and terraces and tree plant in the upper catchment.

\subsection{Antananarivo - Madagascar}

\subsubsection{Background}

The city of Antananarivo consists of a central urban district surrounded by peri-urban settlements and rice farms. The central districts are not segregated by income; large houses are surrounded by high density informal low-income houses. These central districts are on the right bank of the River Ikapo and have protection from 1 in 100 year flood events, while the peri-urban areas on the left bank only have protection from 1 in 10 year floods. The city is drained by 3 main drains which are inadequately maintained and flood throughout the rainy season. Eight low-income communities were visited; four urban and four peri-urban. Water User Associations in these communities buy water from the water utility and sell it from kiosks. Sanitation facilities are pit latrines, although there is a sanitation marketing programme promoting sanplats. Solid waste management is limited. 


\subsubsection{Climate Change}

The mean temperature is expected to increase; by 2055 the south of the country will be $2.6^{\circ} \mathrm{C}$ warmer and the north and coastal areas $1.1^{\circ} \mathrm{C}$ warmer ${ }^{45}$. Mean rainfall and rainfall intensity will increase throughout the summer months, during the winter months the north will be wetter with more frequent storms while the south will be drier. Unusually, these predictions for the future are the reverse of the current trend. The frequency of cyclones is expected to decrease in the early part of the main season but their intensity and destructive power are expected to increase towards the end of the century.

\subsubsection{Hydrological Scenario}

All the climate models predict that Anatananarivo will experience increases in total rainfall and intensity - hence this was the only hydrological scenario considered. . An increase in total rainfall is likely to increase runoff and raise river levels, while increases in rainfall intensity are likely to cause more intense floods from the river and the drains. Even if the frequency of flooding does not change, the increase in river levels will increase the number of days when the city drains cannot drain naturally and have to be pumped. If the pumps fail or are overwhelmed, flooding will occur.

\subsubsection{Vulnerabilities and Impacts}

In the informal urban areas the frequency and severity of flooding from the drains is likely to increase. Flooding is a major health risk and disrupts the lives of communities. Water gets into houses, employment decreases, travel is difficult and the environment becomes dirty, odorous and very unpleasant. Household latrines overflow, their superstructures and pits collapse, the use of flying toilets increases (defecation in plastic bags), there are long queues at kiosks, taps can be submerged and the water pressure is lower. The water supplied by the water utility (JIRAMA) is contaminated during heavy rains. Deforestation in the catchment means there is soil erosion, so increased sediment enters the water treatment works, along with other pollutants as there is no catchment protection.

The upland peri-urban areas may experience increased surface runoff while the lowlands and rice paddies could flood from the drains or river. The impacts would be similar to the urban areas, with the addition of damage to crops and livestock and greater livelihood vulnerability. However, in the peri-urban areas there is typically more space to implement local coping mechanisms.

\subsubsection{Climate Proofing}

There is already an awareness of the importance of addressing the poor sewage and storm water management in Antananarivo and a Sanitation Master Plan has been developed. The

\footnotetext{
${ }^{45}$ Conservation International and WWF (2008), Assessing the impacts of climate change on Madagascar's biodiversity and livelihoods a workshop report. Conservation International. WWF. USAID. MacArthrur. Available at: marineclimatechange.com/Marine_Climate_Change_Workshops/Madagascar_files/CIWWF\%20Madagascar\%20Workshop\%20Report\%20FINAL.pdf (Accessed: October 2010).
} 
adaptation priority should be supporting this existing plan, emphasising that flood risk will become more significant and more resources should be dedicated to flood mitigation. Additional adaptations were also identified for 40 areas modelled ${ }^{46}$ as especially vulnerable to flooding. In these areas water providers should monitor water quality, chlorinate and provide education on flood proofing latrines. The water utility (JIRAMA) should undertake a programme of leak detection, pipe maintenance and reduce illegal connections to minimise contamination of the water supply and improve the hydrostatic pressure. Their treatment system also requires additional stages to cope with the high sediment load in the inlet water during floods. The municipality need to focus on clearing the drains and assisting the other organisations responsible for drainage. They should improve solid waste management and sanitation to reduce dumping in drains. It is also important that they stop people settling on flood prone areas. These ideas need mainstreaming into the plans and actions of the stakeholders. Some additional funding will also be required. Both of these are challenging given the current unstable political situation.

\subsection{Climate Change Awareness}

During the three case studies the overall awareness to climate change was qualitatively reviewed; the results for the different stakeholder groups are summarised in Table 3. Local institutions, water utilities and communities in the three cities were mostly unaware of climate change and have few plans to adapt. In government there is generally some awareness at the policy level, but little impact on the ground. However, even in high-income countries awareness of climate change can be lacking at all levels, for example Tompkins et al (2010) found that in the UK, climate change adaptation had been dominated by national government initiatives and little had trickled down to a local government level ${ }^{47}$.

Table 3 Stakeholders awareness of climate change and their plans to adapt

\begin{tabular}{|l|l|l|c|}
\hline Stakeholder & Awareness & Plans/Actions & $\begin{array}{l}\text { No. } \\
\text { Interviews }\end{array}$ \\
\hline Community & Limited & None & 30 \\
\hline $\begin{array}{l}\text { Local } \\
\text { service } \\
\text { providers }\end{array}$ & $\begin{array}{l}\text { Limited- } \\
\text { Medium }\end{array}$ & No direct plans & 26 \\
\hline Utility & $\begin{array}{l}\text { Limited- } \\
\text { Medium }\end{array}$ & No plans - aware need to adapt system but no direct plans & 5 \\
\hline Council & Medium & No direct plans - Lusaka council has climate change department & 7 \\
\hline Government & $\begin{array}{l}\text { Awareness at } \\
\text { policy level } \\
\text { but little } \\
\text { implementati } \\
\text { on }\end{array}$ & $\begin{array}{l}\text { Involved in UNFCCC dialogue } \\
\text { Some form of climate change department/networking } \\
\text { organisation } \\
\text { REDD process (deforestation) } \\
\text { Little regional or district work being completed, seen as } \\
\text { issue for central government }\end{array}$ & 19 \\
\hline Researchers & High & Studies being undertaken and advocacy work & 3 \\
\hline
\end{tabular}

\footnotetext{
${ }^{46}$ SOMEAH (2010), Outlining a sanitation strategic plan for the agglomeration of Antananarivo. Phase 1: assessment of the sanitation situation. 20127 R1. WSUP Madagascar.

${ }^{47}$ Tompkins, E. L., Adger, N., Boyd, E. G., Nicholson-Cole, S., Weatherhead, E. K. \& Arnell, N. W. (2010) Observed adaptation to climate change: UK evidence of transition to a well-adapting society. Global Environmental Change, 20 (4) 627-635.
} 


\begin{tabular}{|l|l|r|c|}
\hline NGOs & $\begin{array}{l}\text { Most have } \\
\text { high } \\
\begin{array}{l}\text { awareness, } \\
\text { but some are } \\
\text { limited }\end{array}\end{array}$ & - No direct plans & 14 \\
\hline Consultants & Medium & No current projects & 2 \\
\hline $\begin{array}{l}\text { Local } \\
\text { business }\end{array}$ & High & Aware of need to incorporate the impacts & 2 \\
\hline
\end{tabular}

\section{Discussion}

\subsection{Commonalities between Case Studies}

In all the case studies, floods had a bigger impact than droughts, and the interviewees' perception was that changes in mean temperature would have no impact on water and sanitation. Of the 11 communities visited, 8 were vulnerable to flooding and 4 to water shortages. Table 4 presents impacts common across the communities, divided into impacts within the community, and impacts outside the community (on a city-wide, regional or national scale). These impacts outside the community can have a larger overall effect as they affect more people, cause more damage and often rely on resolution by governments and institutions; for example, during a regional drought everyone is impacted by food price increases.

Table 4 Impacts on the low-income urban areas

\begin{tabular}{|c|c|c|}
\hline & Flooding & Droughts \\
\hline 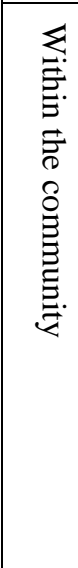 & $\begin{array}{ll}- & \text { Pipes exposed } \\
- & \text { Taps submerged } \\
- & \text { Siltation of water resources } \\
\text { - } & \text { Contamination of boreholes } \\
- & \text { Latrines inundated } \\
\text { - } & \text { Latrines and buildings collapse } \\
- & \text { Solid waste dispersed } \\
- & \text { Water in houses } \\
- & \text { Roads impassable, increasing the cost of } \\
\text { - } & \text { charcoal and food } \\
\text { - } & \text { dysease increases, especially malaria, } \\
- & \text { Employment decreases } \\
\text { Income generating activity decreased }\end{array}$ & $\begin{array}{ll}- & \text { Water shortages } \\
- & \text { Water price increases } \\
- & \text { Less water for health and hygiene } \\
- & \text { Long queues at kiosks } \\
- & \text { Water pressure drops } \\
- & \text { Livestock suffer } \\
- & \text { Peri-urban and garden crops destroyed } \\
- & \text { Increased poverty } \\
- & \text { Education suffers (less money for school } \\
- & \text { fees) } \\
- & \text { Malnutrition } \\
\end{array}$ \\
\hline 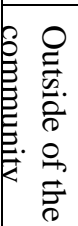 & $\begin{array}{ll} & \text { Utility infrastructure damaged } \\
\text { - } & \text { Increased water treatment costs } \\
- & \text { Crops damaged } \\
- & \text { Road network damaged } \\
- & \end{array}$ & 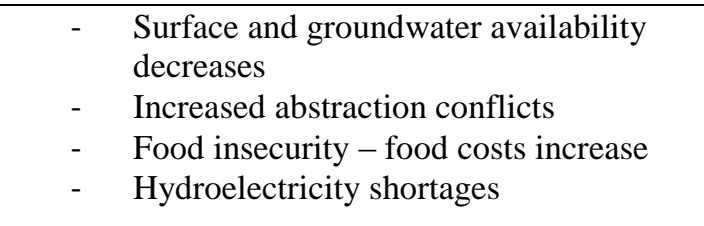 \\
\hline
\end{tabular}


The adaptations recommended can be split between adaptations to droughts and floods, and whether to be undertaken by local service providers, utilities or municipalities. They are specific to each city, and can be found in full in the city specific reports, ${ }^{48}$ These common adaptations (Table 5) are a mixture of infrastructure, monitoring programmes and education. They demonstrate that adapting to climate change does not involve many new processes most adaptations could equally be described as good practice in flood or drought prone areas.

Table 5 Common adaptations recommended for areas at risk to flooding or drought

\begin{tabular}{|c|c|c|}
\hline & Risk of Water Shortages (droughts) & Risk of Floods \\
\hline 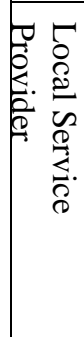 & $\begin{array}{l}\text { - Ensure affordable and accessible water } \\
\text { supply } \\
\text { - Expand kiosk network into unserved areas } \\
\text { - Investigate alternative supplies to use } \\
\text { during droughts } \\
\text { - Community education and hygiene } \\
\text { promotion on the risks to health during } \\
\text { droughts }\end{array}$ & $\begin{array}{l}\text { - Community education and hygiene promotion on the } \\
\text { risks associated with floods } \\
\text { - Education on best practice for latrine construction to } \\
\text { avoid latrines collapsing or overflowing } \\
\text { - Protect boreholes and pipe network from flooding } \\
\text { - Regular sanitary inspections during floods } \\
\text { - Tighter enforcement against fly tipping } \\
\text { - Chlorinate water supply during floods }\end{array}$ \\
\hline$\underset{\Xi}{\stackrel{\Xi}{\rightleftarrows}}$ & $\begin{array}{l}\text { - Support the expansion of new kiosks } \\
\text { - Build new storage tanks } \\
\text { - Investigate the recharge rate/sustainable } \\
\text { yield of aquifers }\end{array}$ & $\begin{array}{l}\text { - Leak detection and pipe maintenance } \\
\text { - Reduce illegal connections and improve the hydrostatic } \\
\text { pressure } \\
\text { - Monitoring water quality during floods } \\
\text { - Regular inspection of infrastructure during floods }\end{array}$ \\
\hline 光. & - Engage in water allocation dialogues & $\begin{array}{l}\text { - Improve drainage systems: clear and maintain drains, } \\
\text { legislation against dumping } \\
\text { - Improve solid waste collection } \\
\text { - Subsidise tanker/waste disposal options } \\
\text { - Land management activities to reduce severity of } \\
\text { floods }\end{array}$ \\
\hline
\end{tabular}

\subsection{Implications of Findings}

Figure 1 synthesises how changes in rainfall (identified as the most significant climate change) impact flood and drought prone areas. There will be some benefits associated with climate change, for example, increased rainfall will have a positive impact on communities in drought prone areas. However, in most cases the negative aspects will be more significant and even for drier futures, if the frequency and intensity of extreme storms rises, flooding may not reduce.

\footnotetext{
${ }^{48}$ See reference 41. Heath et al 2010a; See reference 42. Heath et al 2010b; See reference 43. Heath et al 2010c
} 
Increased

Negative impacts

Minimal Ir

rainfall intensity

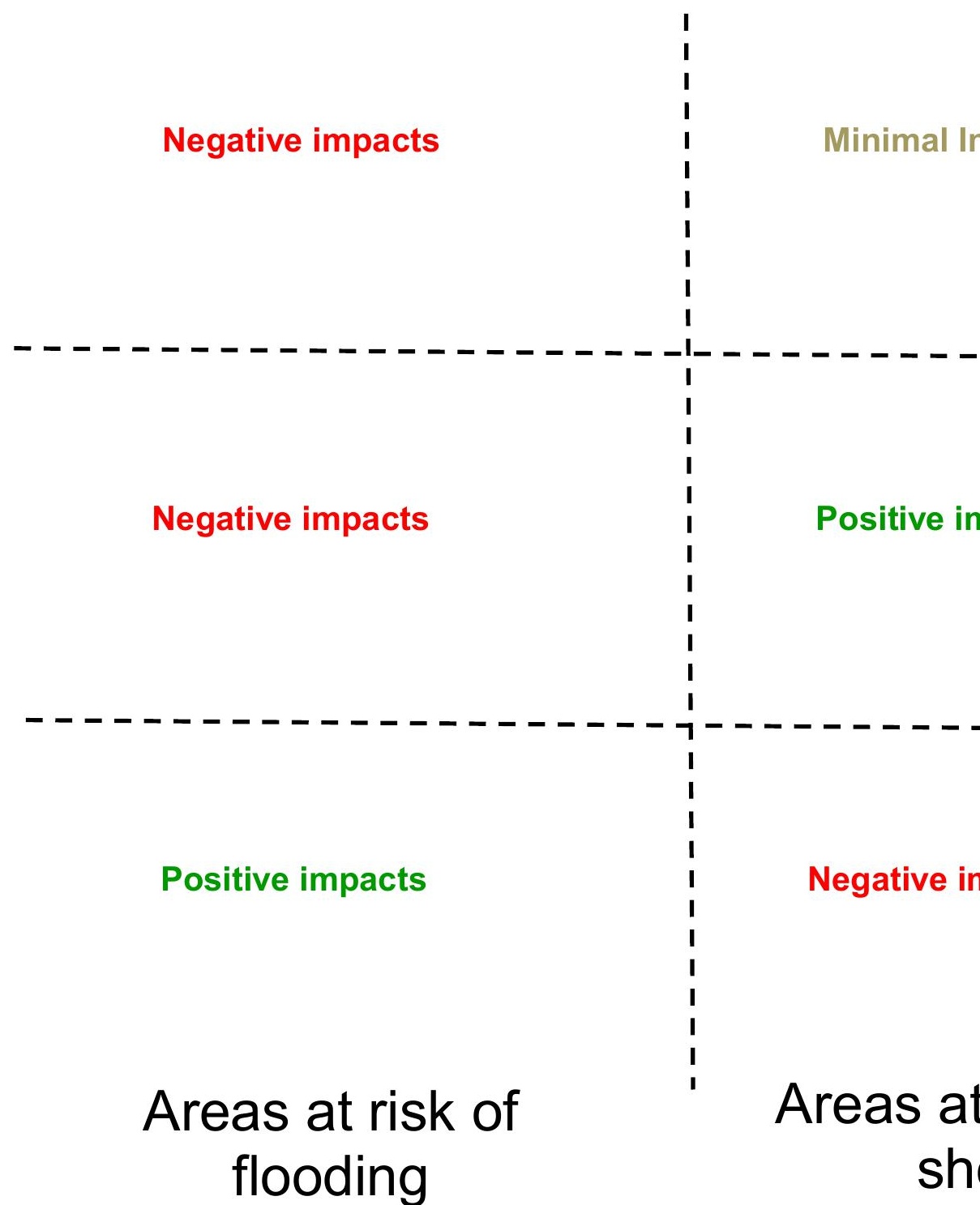

Figure 1 Impacts of climate change on flood and drought prone urban areas

The results indicate that it is increases in extreme events rather than changes in averages that which will cause the most damage to communities and infrastructure, at least in the enxt few decades. This conclusion is shared with the CAPNET (2003) ${ }^{49}$ climate change adaptation guide, which emphasises building capacity to deal with unpredictable events, managing risk and prioritising no-regret measures. An increased frequency of extreme events will introduce risks to projects not designed for by current infrastructure. In particular, increases in rainfall intensity are likely to affect flooding and drainage, for example there may be a higher risk of borehole contamination after heavy rainfall. Examples from regions with experience of the more extreme climates will be increasingly helpful to organisations planning adaptations, as they can provide details of potential risks and design features.

${ }^{49}$ CAPNET (2009), IWRM as a Tool for Adaptation to Climate Change. Training Manual and Facilitator's Guide. REDICA, Cap-Net Brasil, APFM/WMO and UNESCO-IHE. Available at: www.cap-net.org/node/1628 (Accessed March 2010). 
The results support the findings of Sanchez-Rodriguez ${ }^{50}$ and Simon ${ }^{51}$ that for adaptation to be successful it needs to be integrated within existing plans and prioritised alongside other risks. For example, the Sanitation Master Plan in Antananarivo provides a comprehensive overview of how to adapt to flooding and the roles of the different stakeholders, based on detailed research. If adaptations are developed externally they are unlikely to capture the more nuanced details of a locally prepared plan, and may introduce competition and confusion. Many adaptation practises are simply good water management. In Lusaka in particular service providers have been advised to make similar changes for decades; climate change may prove to be the catalyst for getting change to happen.

Jabeen et al. (2009) ${ }^{52}$ found that the poor have a certain level of built-in resilience (preventative and impact minimising economic strategies, asset accumulations, and social support networks) which must be recognised and better supported by planning initiatives. However, for the communities visited it was found that the level of built-in resilience was minimal, due to limited assets and resources. This is compounded by the poor services they receive with respect to water, sanitation, drainage and solid waste collection. A limited education also traps people in a cycle of poverty and sentences them to life in informal settlements.

The limited climate awareness of stakeholders reinforces the need for a rapid and affordable method to assess the impacts of climate change at both the vulnerability and modelling level, to identify pragmatic and rigorous daptations to climate change. This is supported by the findings of Satterthwaite et al. ${ }^{53}$ that local government fail to efficiently address the impacts of climate change. Sanchez-Rodriguez ${ }^{54}$ similarly found that a thorough vulnerability analysis and impact assessment for enabling appropriate design and implementation of adaptation measures is lacking in almost all low- and middle-income countries. Muller ${ }^{55}$ also found that few countries have begun to review their design standards from a climate change perspective. Adaptations which also help reduce vulnerability to current problems will help mitigate opposition to spending on adaptation for the longer-term, and allow a quicker start. This is especially important as the infrastructure built today locks providers into patterns of behaviour for many years to come ${ }^{56}$.

\subsection{Evaluation of the RCAA method}

Essentially, the RCAA identifies the adaptations that local service providers should implement to increase their climate resilience, and the adaptations required by the utility and

\footnotetext{
${ }^{50}$ See reference 25, Sanchez-Rodiguez (2009).

${ }^{51}$ See reference 25, Simon (2010).

${ }^{52}$ Allen, A., Johnson, C. and Jabeen, H. (2009), Built-in resilience: learning from grassroot coping strategies for climate variability. Environment and Urbanization. 22 (2) pp. 415-431.

${ }^{53}$ Satterthwaite, D., Huq, S., Pelling, M., Reid, H., \& Romero Lankao, P. (2007), Adapting to climate change in urban areas: The possibilities and constraints in low- and middle income nations. London: International Institute for Environment and Development. Available at: pubs.iied.org/10549IIED.html (Accessed: January 2010).

${ }_{55}^{54}$ See reference 25, Sanchez-Rodiguez (2009).

55 See reference 24, Muller (2007).

${ }^{56}$ See reference 24, Muller (2007).
} 
municipality to support them. Its main strengths are that it applies regional climate modelling to local vulnerabilities, it is based on multiple scenarios describing the possible impacts of possible futures and it was developed and trialled based on field work, ensuring it is workable and relevant. The RCAA draws heavily upon the Vision 2030 overview of the vulnerabilities of water and sanitation technology and potential adaptations, but integrates them within the context of the existing vulnerabilities. The RCAA incorporates the community approach used in CRiSTAL and the assessment of existing climate vulnerabilities used by USAID. However, the RCAA does have limitations and these are outlined for each stage below.

\subsubsection{Limitations}

The uncertainties associated with climate modelling make it difficult to quantify the climate changes at local level and dangerous to rely on detailed scenarios. Changes to tropical precipitation are particularly uncertain due to uncertainties with the positioning of the Intertropical Convergence Zone ${ }^{57}$. Climate predictions are ideally given as probabilities or as most likely values with wide ranges. This uncertainty is often magnified when calculating the impacts. The climate uncertainty is even greater at the city scale as there has been little downscaling of the models and the predictions are based on interpolations. The exception for this study was in Madagascar where there had been detailed modelling and analysis of the region.

In Lusaka and Naivasha, community data was collected using individual interviews, while focus groups were used in Antananarivo. The questions asked were the same throughout, but the focus groups proved to be a more efficient way of getting information: a broader range of impacts were identified, and groups often verified their answers through the discussions. It was difficult with both methods to explore the impacts of possible new risks as the community had direct experience. However, it is worth noting that Adelekan $(2010)^{58}$ had success in obtaining specific data on flooding impacts in Lagos (Nigeria) through individual interviews using local enumerators. Similarly, Douglas et al $(2008)^{59}$ used a technique developed by ActionAid called Participatory Vulnerability Analysis which explored the reasons for flooding and what community action is possible. Their local representatives obtained some vivid descriptions of how individuals reacted to the flooding. From these examples it becomes clear that local interviewers can get better information than external ones; however training local interviewers may not be possible within the short timescale of an RCAA commissioned by an external agency. It was difficult however to explore the impacts of possible new risks as the community had not directly experienced the effects.

The interviews with more educated individuals including community leaders were more insightful, requiring less probing to highlight secondary issues. The main limitation was that

\footnotetext{
${ }^{57}$ McSweeney, C.,New, M., Lizcano, G., \& Lu, X. (2010), The UNDP Climate Change Country Profiles Improving the Accessibility of Observed and Projected Climate Information for Studies of Climate Change in Developing Countries. American Meteorological Society 2 pp. 157-166.

58 Adelekan, I.O. (2010), "Vulnerability of poor urban coastal communities to flooding in Lagos, Nigeria", Environment and Urbanization, 22, (2) pp 433-450

${ }^{59}$ Douglas, I., Alam,K., Maghenda, M. Mcdonnell,Y., McLean, L. \& Campbell, J. (2008), "Unjust waters: climate change, flooding and the urban poor in Africa", Environment and Urbanization 20 1, pp 187-206.
} 
more relevant concepts emerged as interviews progressed, so that discussion of these was missed with early informants. To address this, some of the stakeholders were interviewed again at the end of the fieldwork.

Converting the climate changes into local impacts is the most uncertain aspect of the RCAA, largely due to the lack or low quality of hydrological and climate data. A conceptual hydrological model based on hydrological principles was developed and used to define scenarios for the various climate projections. However, great uncertainty remains in estimating the effect on infiltration (affecting both recharge and runoff) due to the interrelated nature of hydrological processes, especially when rainfall volume is predicted to decrease while its intensity increases. This is significant as small changes in rainfall and/or intensity are amplified in the catchment response, often leading to large changes in stream flow ${ }^{60}$.

The assessments of the impacts of the scenarios provided a clear insight into the nature of the risks; however, sometimes the intensity of the impacts was difficult to clarify. Likewise, most of the climate proofing process effectively identified appropriate adaptations, but for some impacts there was insufficient knowledge of the system design, layout and soil structure or insufficient information on existing plans to provide detailed specifications. This could be addressed by focusing on these aspects during subsequent field work.

The main external limitations are that the water and sanitation services to be climate proofed are mostly in informal settlements in urban or peri-urban areas where there are lower income levels and deficient basic services. The tariffs collected often do not cover operation and maintenance costs, let alone provide revenue for future investments. Therefore climate change adaptations will often be secondary to providing basic supplies and meeting current needs. However, it should be noted that when populations migrate to cities from areas experiencing extreme environmental change this may present opportunities for them to receive better services and become less vulnerable overall. ${ }^{61}$

\section{Conclusion}

The lack of climate change awareness in low- and middle-income means it is essential to have a simple method to climate proof water and sanitation services for the urban poor in these countries. The main risks to water and sanitation provision are from changes to the frequency and intensity of extreme hydrological events, especially an increase in floods or droughts. The RCAA is an effective tool for climate proofing, as it converts regional climate predictions into local adaptations. In addition, by dividing adaptations between the stakeholders, awareness is raised at the appropriate levels.

Applying the RCAA highlighted that adapting to climate change does not necessarily involve many entirely new processes or techniques; instead it requires a combination of capacity

\footnotetext{
${ }^{60}$ See reference 24, Muller (2007).

${ }^{61}$ Foresight: Migration and Global Environmental Change (2011), Final Project Report, The Government Office for Science, London
} 
building, technological and managerial measures. Water providers should not consider climate change in isolation, but rank and prioritise it against other sources of change, risk and uncertainty. They need to focus on increasing the environmental resilience and disaster preparedness of projects and the robustness of existing systems. It should, however, be made clear that this is not an argument for 'business as usual' and climate change adaptations should not simply be 'bolted on' to existing plans. In particular, risks arising from increases in rainfall intensity and more frequent extreme events should be considered. 